8. Губина, Н. В. Роман «Бич божий»- вершина творческой эволюции Е. И. Замятина // Мир науки, культуры, образования. - 2017. - № 6. - С. 487-489.

9. Репина, Т. К семантике центрального образа в стихотворении Ю. Левитанского «Квадратный человек» // Запасник. - 2011. - № 3. - URL: http://www.promegalit.ru/publics.php?id=3029 (дата обращения: 02.03.19).

Nina $V$. Gubina, Ph. D. in Philology Altai State Institute of Culture (Barnaul, Russia) ninochka4@mail.ru

Liubov' $V$. Slobodina

Altai State Institute of Culture (Barnaul, Russia) lu64sol@yandex.ru

\title{
CINEMATOGRAPHIC TECHNIQUES IN POETIC RECEPTION OF YURI LEVITANSKY
}

\begin{abstract}
The article reflects specific of applying of artistic techniques of motion picture art in arranging poetic text in "Cinematograph" (1970), a book of poetry written by Yuri Levitansky (1922-1996), Soviet and Russian poet, interpreter, State Prize of the Russian Federation in Literature and Art winner. On the authors' view, poet addresses to expressive means of cinema to line up space-time model and an image structure of the collection of poems, to make visible poet's own intention and to navigate a reader's attention with a set of artistic and technic tools get from a field of film production, such as frame-by-frame cross-cutting, focusing, camera zoom in, table of content as a film's credits, etc. Analysis of metatext of headlines of the book reveals their cycling, that points out on the poet's orientation on "death/resurrection" mythological model. The authors of the article point subject group of the book's headlines and through it analyze images of Ironic Human and Square Human, the key characters of eternal motion picture strip of life.

Keywords: Yuri Levitansky, “Cinematograph” (book of poetry), visualization, synthesis of arts, an author's idea, a reader's response, cross-cutting, metatext, a narrator (persona).
\end{abstract}

УДК 78:[061.231:7.071.1](571.51)

DOI: 10.32340/2414-9101-2019-4-29-34

А. В. Заозерских

Сибирский государственный институт искусств им. Дмитрия Хворостовского (Красноярск, Россия) alyona61193@mail.ru

Научный руководитель - М. М. Чихачёва, кандидат искусствоведения, доцент Сибирский государственный институт искусств им. Дмитрия Хворостовского (Красноярск, Россия) mgokhfeld@yandex.ru

\section{МЕМОРИАЛЬНАЯ МУЗЫКА КОМПОЗИТОРОВ КРАСНОЯРСКОЙ ОРГАНИЗАЦИИ «СОЮЗ КОМПОЗИТОРОВ РОССИИ»}

Исследование выполнено при поддержке Красноярского краевого фонда поддержки научной и научно-технической деятельности.

Аннотация. Изложена обзорная характеристика специфики мемориальной музыки на примере композиторских работ современных сибирских сочинителей, работающих в жанре академической музыки. Исследователь отмечает устойчивый интерес сибирских авторов к созданию т. н. «музыкальных памятников», художественных опусов in memoriam, в основу композиторского замысла которых положена задача демонстрации уважения ушедшему творческому гению. На примере двух музыкальных сочинений членов Красноярской региональной общественной организации Всероссийской общественной организации «Союз композиторов России» (г. Красноярск, Россия) - «Квартет № 1» (ор. 8) И. Я. Флейшера (род. в 1949 г.), посвящённый памяти советского композитора А. Г. Шнитке (1934-1998 гг.), и «Фантазия памяти А. П. Петрова» В. Е. Карпенко (род. в 1958 г.) - автор статьи раскрывает некоторые особенности композиторской техники и комбинации средств музыкальной выразительности, замеченные в музыкальных текстах, посвящённых памяти той или иной ушедшей персоны.

Ключевые слова: мемориальная музыка, музыкальные произведения іп тетогіат, aдресат музыкальных сочинений іп тетогіат, память в искусстве, современные сибирские композиторы, компо- 
зиторы Красноярской региональной общественной организации Всероссийской общественной организаиии «Союз композиторов России», И. Я. Флейшер (композитор), В. Е. Карпенко (композитор), А. Г. Шнитке (композитор), А. П. Петров (композитор).

Мемориальность является одной из значимых тематических сфер современной отечественной музыки, в том числе отмеченной и исследовательским вниманием. Мемориальные опусы встречаются как у композиторов ведущих отечественных школ (представителей Москвы и Санкт-Петербурга), так и у региональных композиторов.

Музыка памяти является одной из ведущих тематических сфер творчества композиторов Сибири (композиторы Новосибирска, Абакана, Барнаула, Омска, Иркутска, Красноярска и др.) [1]. К сожалению, лишь немногие исследования освещают тематическую сферу памяти в творчестве сибирских авторов, в том числе и в музыке композиторов, входящих в состав Красноярской организации «Союз композиторов России».

Музыка памяти представлена у следующих композиторов красноярской организации: В. Е. Карпенко. Трио №1 (Три пьесы) памяти Б. Бриттена (1977), Фантазия для симфонического оркестра памяти А. П. Петрова (2007); В. А. Бешевли. Струнный квартет №2 в 3 частях (посвящается памяти моего дяди Э. А. Ганжерли) (1980); О. Л. Проститов. Симфония для камерного оркестра №2 памяти И. Стравинского (1983), Терцет для двух скрипок и фортепиано, посвящённый жертвам октября 1993 года (1993), «Ламенто Памяти Великого Мастера» для оркестра, женского хора, фортепиано и органа, посвященное памяти А. П. Петрова (2007); О. И. Меремкулов. Композиция для виолончели соло «Памяти архитектора Матвея Казакова» (1990); И. Я. Флейшер. Струнный квартет № 1, op. 8 (памяти А. Г. Шнитке) (2000), Вокализ «Памяти павших», ор. 23 (2004), «Бранденбургская фантазия» для солирующего альта, струнного оркестра и клавесина (памяти Ю. М. Крамарова) ор. 64 (2011), «Музыкальное приношение» (памяти И. Урьяша) для двух скрипок и камерного оркестра, op. 78 (2014), Прелюдия до минор для струнного квартета (памяти Ю. Н. Мазченко) ор. 129 (2019). Прежде всего, это посвящения близким людям, знаковым фигурам эпохи (творческим личностям), историческим событиям.

Рассмотрим два сибирских мемориальных посвящения выдающимся композиторам второй половины XX века: Альфреду Гарриевичу Шнитке (1934-1998 г.) и Андрею Павловичу Петрову (19302006 гг.).

Альфред Гарриевич Шнитке ушёл из жизни в 1998 г., и многие авторы в память об Альфреде Гарриевиче обратились в своем творчестве к мемориальным музыкальным «откликам»: Е. И. Подгайц. «Фантазия памяти Альфреда Шнитке» для баяна соло (набросок его биографии до последнего вздоха); Дж. Ноймайер. Балет «Звуки пустых страниц», посвящённый судьбе композитора, на музыку Альтового концерта Шнитке (был поставлен в Мариинском театре, удостоен российской премии «Золотая маска»). Также памяти А. Г. Шнитке посвящены пьеса Р. С. Леденева «Тишина» для скрипки соло, а также сочинения С. М. Слонимского: «Один день жизни», кантата на текст из древнеиндийской «Дхаммапады», Шесть романсов на слова М. Лермонтова и Г. Державина.

Сибирским посвящением памяти А. Г. Шнитке стал Квартет №1, или «Анданте, Бурлеска и Вальс» соч. 8, красноярского композитора Игоря Яковлевича Флейшера ${ }^{1}$ (2000).

Квартет написан для классического состава: 2 скрипки, альт, виолончель. Сочинение включает три части - «Анданте», «Бурлеска» и «Вальс», - после проведения которых «Бурлеска» повторяется D.C. al Fine (авторское указание) $)^{2}$. Тем самым, «оформляется» классическая 4-частная форма квартета. (Сам композитор настаивает на трёхчастной трактовке сочинения, несмотря на повторение части.)

Игорь Яковлевич в личной беседе ${ }^{3}$ объяснил мемориальное посвящение А. Шнитке интересом к его творчеству, который усилился в начале 2000-х гг.: «Этот автор, по моему мнению, является одним из лучших отечественных композиторов XX века, наряду с Прокофьевым и Шостаковичем. <...> Когда я услышал его музыку, я начал понимать трагичность «высказывания» Шнитке. Я хорошо знаком со многими сочинениями Альфреда Гарриевича. Среди таковых Concerto grosso № 2 для скрипки и виолончели. Это потрясающее сочинение. Я его слушал в день по несколько раз. Столь же

\footnotetext{
${ }^{1}$ Игорь Яковлевич Флейшер - красноярский композитор, член Красноярской организации «Союз композиторов РФ», выдающийся альтист, заслуженный артист РФ, профессор.

2 Части исполняются attacca.

${ }^{3}$ В статье представлены материалы из личного архива автора статьи: интервью с И. Я. Флейшером и переписка с В. Е. Карпенко.
} 
глобальным его сочинением для меня является Альтовый концерт. И еще одно произведение, которое потрясло меня - кантата «История доктора Иоганна Фауста» на текст из «Народной книги». Музыкальный язык Альфреда Шнитке уникален. Лично, к сожалению, я не был знаком с Альфредом Гарриевичем, но при написании квартета у меня сразу была задумка сочинения памяти этого автора».

Квартет открывается частью «Анданте». Игорь Яковлевич так описывает его содержание: «Похороны бывают разные. "Анданте" - это "подготовка" его [Шнитке] жизни к смерти... Естественно, при сочинении я не мог не использовать интонации А. Г. Шнитке». Автор вводит реминисценцию мотива из Concerto grosso № 2 для скрипки и виолончели с оркестром адресата посвящения и аллюзию на мотивы арии Мефистофеля из кантаты.

Говоря о жанре Concerto grosso в творчестве самого А. Г. Шнитке, можно сказать, что это своего рода «музыкальное приношение» И. С. Баху и своеобразный пример полистилистики, обращение к жанру эпохи барокко. Таким образом, в Квартете реализуется своеобразный полилог музыкальных «приношений»: И. Я. Флейшер - А. Г. Шнитке - И. С. Бах.

Образный строй 1-й части представляет светлую скорбь от ухода выдающегося композитора. Часть начинается проведением тематического материала в партии альтов с последующим «включением» всех инструментов квартета. Особая атмосфера возникает благодаря комплексу музыкальновыразительных средств: «приглушенное» звучание квартета (только в кульминации используется динамика sf), «разряженная» фактура, несколько раз возникающие нисходящие малосекундовые ходы. Даже введение интонаций из арии Мефистофеля не воспринимается как внедрение «дьявольского» начала: в медленном темпе, динамике mp (в партии альта, а затем вторых скрипок), эти интонации окрашиваются в светлые тона высказывания в память о композиторе.

При этом введение аллюзии арии Мефистофеля из кантаты Шнитке «Гибель Фауста» воспринимается как символ смерти. Как отмечает В. Н. Холопова: «Самое решительное и радикальное, на что подвигся здесь Шнитке, - это “ария” контральто в жанре танго в кульминационном эпизоде кантаты №7 (Гибель Фауста). Решение стоило композитору больших душевных терзаний. < ..> Унижающее танго в №7 кантаты «Фауст» представлено в его самом натуральном виде: эстрадно-страстный голос, доходчивая мелодия, чувственно-развязный синкопический ритм аккомпанемента, явная тональность (соль минор), танцевальные квадраты структуры, под стать всему - солирующие саксофоны и томные глиссандо у солистки» [2, с. 180].

2-я часть квартета И. Я. Флейшера «Бурлеска» представляет собой гротескную зарисовку окружения Альфреда Гарриевича. Как говорит сам Игорь Яковлевич, здесь изображена «человеческая шелуха, мешавшая жить Шнитке», музыку которого в СССР практически не исполняли и не издавали.

Эта часть резко контрастна предыдущей: тональность соль минор (в которой написана ария Мефистофеля), темп Allegro molto, остинатное движение короткими длительностями, острые глиссандирующие интонации, большие скачки, имитации едкого смеха в мелодии - всё это характеризует образ «зла». Остинатное движение задается сначала шестнадцатыми, а затем и восьмыми в малосекундовом звучании в партиях вторых скрипок и альтов. Такое обращение к данному типу дв ижения отсылает к «приземленному» пространству; диссонантное звучание добавляет «резкие» краски в данное изображение порочного общества. Заканчивается часть выдержанным тоническим трезвучием в динамике sff.

Вслед за «Бурлеской» следует «Вальс», который представлен здесь в нетипичном для данного жанра темпе Lento. По словам И. Я. Флейшера, этот вальс можно назвать «похоронным, хотя такой эпитет кажется несопоставимым с данным жанром». Введение именно жанра вальса в данное сочинение композитор связывает с финалом кантаты «История доктора Иоганна Фауста». В завершении кантаты звучат «отзвуки» аккомпанемента вальса в исполнении фортепиано. Кроме того, жанр вальса связывают с жанрами, которые приобрели образно-смысловую трактовку мемориальной музыки, что отмечает исследователь Т. С. Андрущак в диссертационной работе «Мемориальность в отечественной музыке последней трети XX века (к исследованию феномена)» [3]. Именно такой музыкально-содержательный образ складывается не только благодаря очень медленному темпу; введение приема non vibrato помогает воссоздать неземное, «п отустороннее» звучание.

Ещё одна знаковая черта мемориальной музыки, проявившаяся в 3-й части квартета, - жанровые признаки колыбельной: хроматические «покачивания» (на основе малосекундовых нисходящих интонаций) и арпеджированное движение pizzicato в сопровождении мелодии. Жанр колыбельной в та- 
ком контексте символичен: характеризует образ сна как смерти. Ремарка un poco steso (немного растягивая) способствует ещё большему эмоциональному погружению в состояние скорби.

Повторение «Бурлески» da саро символизирует возвращение сферы гротеска. Как комментирует И. Я. Флейшер: даже после ухода композитора остаются те «нелюди», которые «мешают жить и творить».

Примером несколько иной трактовки «музыки памяти» является «Фантазия для симфонического оркестра памяти А. П. Петрова» В. Е. Карпенко.

Андрей Павлович Петров оказал большое влияние на развития искусства сибирского региона. Именно по инициативе А. П. Петрова, который на тот момент был председателем Ленинградской композиторской организации, было открыто Красноярское отделение Союза композиторов. Андрей Петров присутствовал на торжественном концерте-открытии отделения в Малом концертном зале Красноярской краевой филармонии 11 ноября 1983 г. Он подарил новой организации символический подарок - вывеску для входа в помещение, выделенного для Союза композиторов [4].

При таком взаимодействии естественно, что члены красноярской композиторской организации откликнулись на уход А. П. Петрова (2006 г.). В 2007 году появляются два сочинения: О. Л. Проститов. «Ламенто Памяти Великого Мастера» для оркестра, женского хора, фортепиано и органа, посвящённое памяти А. П. Петрова; В. Е. Карпенко. Фантазия для симфонического оркестра памяти А. П. Петрова.

Остановимся на рассмотрении Фантазии В. Е. Карпенко ${ }^{1}$. В этом произведении ярко проявились образы и символы «музыки памяти».

Каждый раздел Фантазии связан с той или иной образной сферой, близкой творчеству Андрея Петрова. Контраст этих образов и средств их музыкального воплощения очень ярок, в чем-то даже эклектичен. Владимир Евгеньевич в личной переписке с автором статьи отмечает: «Трудно говорить о его творчестве [Петрова] в целом, далеко не все знаю, в советское время о нем писали, как об эклектике (что тогда имело негативный характер). “Эклектику” можно поменять на “полистилистику”, это точнее, и укладывается в стилевое многообразие российской музыки XX века».

Тем не менее, в Фантазии выстраивается органичное музыкальное целое, в контрастных разделах которого можно усмотреть смену музыкально-исторических эпох, стилей.

Образы русского эпоса раскрываются в музыке вступления. Связь с архаическим фольклором проявляется в характере мелодии первой темы вступления, которая опирается на трихордовую попевку, развивается по вариантно-вариационному принципу, звучит в проведении у колокола и гобоя. Сумрачный, трагический характер звучания в целом определяется такими средствами музыкальной выразительности, как минорный лад (ре минор), темп Moderato, использование крупных длительностей, введение фригийского оборота (вторая пониженная ступень), тембр колокола (ассоциация с погребальным колоколом).

Смена разделов в образно-смысловом плане ознаменовывается сменой музыкальноисторических эпох. Во вступлении представлен архаичный образ Руси, в первом же разделе - XVIII век. В основе первого раздела лежит цитата исторической народной песни «Нас пугали Пугачем», которая связана с событиями Крестьянской войны под предводительством Е. И. Пугачева 17731775 гг.; композитор не раз обращался к этой теме в написании своих сочинений. Историческая песня «Нас пугали Пугачам» представлена в хрестоматии Н. М. Бачинской и Т. В. Поповой «Русское народное музыкальное творчество» ${ }^{2}$. В предисловии к разделу об исторических песнях по отношению к данному образцу дано следующее пояснение: «В уральской песне "Нас пугали Пугачам" (записанной в Челябинске) Пугачёв подобно Разину собирает вокруг себя ватагу удальцов из голытьбы. В этой песне воспроизводится момент расправы с врагами народа: “А попов всех на костры, а пузатых на бастрык” (на перекладину). Песня исполнялась в быстром темпе, с энергичным, чётко рифмованным напевом» [5, с. 111]. Таким образом, в первом разделе Фантазии воплощается драматичный образ стихийной народной силы.

Слом эпох ознаменовывается переходом к другому разделу и другой музыкально-исторической эпохе - перенос во вторую половину XX века. Средний раздел сложной трёхчастной формы Фантазии представляет собой «лирический додекафонный вальс»³. Именно этот эпизод напрямую связан с

\footnotetext{
${ }^{1}$ Владимир Евгеньевич Карпенко - иркутский композитор, музыковед, художественный руководитель Ансамбля солистов Иркутской филармонии, член Красноярской организации «Союз композиторов РФ».

${ }^{2}$ Именно к этому варианту обращается композитор.

${ }^{3}$ Темповая ремарка Tempo di Valse, ключевые знаки отсутствуют.
} 
музыкой и личностью Андрея Петрова. Жанр вальса здесь выступает и как знак XIX-XX столетий, и как символ творчества Андрея Петрова и Владимира Карпенко. В. Е. Карпенко отмечает, что сам он не раз обращался к написанию додекафонных вальсов, подобных тому, что представлен в Фантазии.

Раздел открывается темой вальса В. Карпенко, представляющего собой серию, изложенную в партиях альта и виолончели. Тема проводится несколько раз в различном воплощении: транспозиция, инверсия, ракоход инверсии. Несмотря на додекафонную основу, образ вальса представляется весьма изящным, лёгким.

Постепенно развитие серии «утихает» и в диалог с вальсом В. Е. Карпенко вступает тема знаменитого вальса А. П. Петрова из к/ф «Берегись автомобиля» (1966). В. Е. Карпенко вводит цитаты из первого и второго разделов вальса. Первая цитата звучит в партии флейты и проводится лишь частично. Такое фрагментарное проведение цитаты воспринимается как напоминание, размышление о фигуре посвящения опуса. Вторая же цитата из среднего раздела вальса Петрова звучит в более широком варианте в партиях гобоя и фагота.

Тем самым, в среднем разделе Фантазии представлен авторский взгляд - осмысление смены музыкально-исторических эпох автором XXI века через жанр вальса, использование серийной техники и цитаты из творчества адресата посвящения.

Третий раздел формы Фантазии представляет собой синтезированную репризу - тематический материал из первого и второго разделов. Таким образом, в репризе соединяются признаки разных эпох, представленных в предыдущих разделах, автор осмысляет их сквозь призму собственного взгляда, взгляда своей эпохи.

В коде композитор вводит ещё одну цитату из творчества А. П. Петрова - фрагмент из музыки к к/ф «Я шагаю по Москве» (1963) в проведении флейты и кларнета. В тексте песни А. Петрова эта фраза соответствует словам: «Бывает всё на свете хорошо». Как отмечает сам В. Карпенко: «Слова заключительной цитаты "Бывает все на свете хорошо" можно буквально считать оптимистическим выводом после всех перипетий». Владимир Евгеньевич так прокомментировал введение цитат А. П. Петрова: «...две цитаты из вальса Петрова всплыли в процессе сочинения у меня внезапно, и сразу появилась и встала на свое место заключительная цитата - итог развития».

После цитированного материала пиццикато у струнных звучит подпись самого Владимира Евгеньевича Карпенко - B-A-Dis-E-D: «Тема пиццикато последних тактов 546-550 - моя подписьВладимир (если писать названия нот на латинском)».

В рассмотренных двух мемориальных опусах композиторов Красноярской организации «Союза композиторов России» нашли яркое воплощение специфические черты мемориальной музыки:

- характерные образно-содержательные комплексы (противопоставление философских категорий жизни и смерти, трагического и просветлённого, воплощение образа пути, света);

- особая жанровая сфера (вальс, колыбельная);

- своеобразная тембровая и штриховая драматургия (тембры колокола, ксилофона, колокольчиков, регистровые сопоставления, non vibrato, тремоло и рizzicato струнных);

- интонационные обороты с мемориальной символикой (малосекундовые нисходящие ходы, фригийский оборот, тритон и другие) [6, с. 41-42].

Важным признаком музыки памяти является воплощаемый диалог между авторами: введение цитат и аллюзий из музыки адресатов посвящения; программная направленность (посвящение, отсылки к словесным и музыкальным текстам). В примерах сибирских мемориальных сочинений И. Я. Флейшера и В. Е. Карпенко представлена попытка диалога-осмысления жизни и творчества двух выдающихся отечественных композиторов А. Г. Шнитке и А. П. Петрова.

Особая роль мемориальной музыки в творчестве композиторов красноярской творческой организации представляет собой значимый вклад сибирских авторов в сохранение «памяти отечественной культуры».

\section{Сиисок литературы}

1. Заозерских, А. В. Музыка «памяти» в творчестве композиторов Сибири / А. В. Заозёрских, М. М. Чихачёва // Вестник музыкальной науки. - 2019. - № 1. - С. 98-104.

2. Холопова, В. Н. Композитор Альфред Шнитке. - Челябинск : Аркаим, 2002. - 253 с. - (Биографические ландшафты). - URL: https://classic-online.ru/uploads/000_books/300/256.pdf (дата обращения: 15.03.2019).

3. Андрущак, Т. С. Мемориальность в отечественной музыке последней трети XX века (к исследованию феномена) : автореф. дисс. ... канд. иск.: 17.00.02. - Саратов, 2008. - 23 с. 
4. Красноярская региональная организация общественной организации «Союз композиторов России» : [обзор фонда Государственного архива Красноярского края]// Архивы Красноярского края : офиц. сайт. Красноярск, 2011-. - URL: http://красноярские-архивы.pф/gosudarstvennyi-arkh/nauchno-spravochnyiapparat/obzory-fondov/701 (дата обращения: 11.03.2019).

5. Бачинская, Н. М. Русское народное музыкальное творчество : хрестоматия / Н. М. Бачинская, Т. В. Попова. - Москва : Музыка, 1974. - 302 с.

6. Заозёрских, А. В. Мемориальные жанры в искусстве (на примере творчества Романа Леденева)/ А. В. Заозёрских, М. М. Чмхачёва // Культура и искусство: поиски и открытия : сб. науч. ст. - Кемерово : Кемеров. гос. инст. культуры, 2017. - С. 39-44.

Alyona V. Zaozyorskikh

Dmitri Hvorostovsky Siberian State Institute of Arts (Krasnoyarsk, Russia) alyona61193@mail.ru

Scientific Chief - Maria M. Chikhachyova, Ph. D. in Art Criticism, Associate Professor Dmitri Hvorostovsky Siberian State Institute of Arts (Krasnoyarsk, Russia) mgokhfeld@yandex.ru

\title{
MUSIC IN MEMORIAM BY MELODISTS FROM KRASNOYARSK REGIONAL PUBLIC ORGANIZATION OF THE RUSSIAN PUBLIC ORGANIZATION "UNION OF COMPOSERS OF RUSSIA"
}

The reported study was funded by Krasnoyarsk Krai Scientific and Research Activities Support Fund

\begin{abstract}
The paper discloses specifics of music in memoriam using modern Siberian classic melodists' works. The author notes sustainable interest of Siberian composers to making "musical monuments", artistic opuses in memoriam that have a task to show respect for another passed genius as a melodist's creative idea. The author of the article reveals some peculiarities of composing techniques, ways of combination of musical expressive means noticed in texts of musical opuses dedicated to the memory of passed artists on the examples of the next two musical pieces written by members of Krasnoyarsk Regional Public Organization of the Russian Public Organization "Union of Composers of Russia" (Krasnoyarsk, Russia) - "Quartet No. I" (op. 8) by Igor Fleisher (1949), dedicated to the memory of Soviet composer Alfred Schnittke (1934-1998), and "Fantasy in memory of Andrei Petrov" by Vladimir Karpenko (1958).

Keywords: music "in memoriam", musical opuses "in memoriam", a narratee for musical composition "in memoriam", memory in art, modern Siberian composers, composers from Krasnoyarsk Regional Public Organization of the Russian Public Organization "Union of Composers of Russia", Igor Fleisher (composer), Vladimir Karpenko (composer), Alfred Schnittke (composer), Andrei Petrov (composer).
\end{abstract}

УДК 82.312-1Толстой+Пастернак]:[782.1:7.071.1Лубченко]

DOI: 10.32340/2414-9101-2019-4-34-39

Д. В. Калинина

Сибирский государственный институт искусств им. Дмитрия Хворостовского

(Красноярск, Россия)

deresel@yandex.ru

\section{«АННА КАРЕНИНА» Л. Н. ТОЛСТОГО И «ДОКТОР ЖИВАГО» Б. Л. ПАСТЕРНАКА - ЛИТЕРАТУРНЫЕ ИСТОЧНИКИ МУЗЫКАЛЬНЫХ ПРОИЗВЕДЕНИЙ А. В. ЛУБЧЕНКО}

Исследование выполнено при поддержке Красноярского краевого фонда поддержки научной и научно-технической деятельности.

Аннотация. Охарактеризован исторический и социально-политический контекст создания признанных шедевров русской и мировой литературы: романа Л. Н. Толстого «Анна Каренина» (18731877 гг.) и романа Б. Л. Пастернака «Доктор Живаго» (1945-1955 гг.), составивших литературную основу для исторической музыкальной драмы в 15 сценах «Доктор Живаго» (ор. 71; 2010 г.) и драматической поэмы для большого симфонического оркестра «Анна Каренина» (ор. 74; 2010 г.) современного российского композитора и дирижёра А. В. Лубченко (род. в 1985 г.). Автор статьи отмечает идейно-художественное созвучие, тематическую и эстетическую близость романов, разделённых более чем полувековой дистанцией, излагает некоторые факты биографии писателей, получившие художественное осмысление в литературных текстах, приводит примеры отзывов современников писа- 